\title{
Duodenal Stenosis Caused by Helicobacter Pylori: Mimicker of Chronic Constipation
}

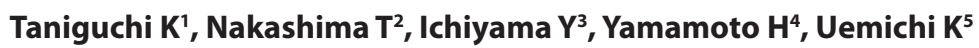

\begin{abstract}
Although the most common causes of childhood chronic constipation are functional, a minority have an organic cause. We report an 11-year-old girl who was diagnosed as chronic constipation, but actually suffered from duodenal stenosis caused by Helicobacter pylori. An enhanced computed tomography was useful for investigation. Duodenal stenosis should be listed as a differential diagnosis for childhood chronic constipation.
\end{abstract}

Key words: Duodenal stenosis, Chronic constipation, Enhanced CT

\section{Introduction}

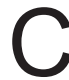
hronic constipation remains one of the most frequent complaints in pediatric clinics ${ }^{1-3}$. Chronic constipation is mainly functional: ${ }^{4}$ very small faction of it is caused by organic disorders ${ }^{3-5}$. Although various differential diagnoses have been reported $^{3,4}$, duodenal stenosis caused by Helicobacter pylori is not well known. Herein we report an 11-year-old girl who was diagnosed as chronic constipation, but actually suffered from duodenal stenosis caused by $H$. pylori.

\section{The Case}

All procedures followed were in accordance with the ethical standards of the responsible committee (Tara Town Hospital, Japan) and with the Helsinki Declaration of 1975, as revised in 2013. Written informed consent was obtained from the family members of the patient for the publication of this report.

An 11-year-old girl with an unremarkable medical history suffered from repeated vomiting, abdominal pain, and constipation. She was diagnosed as chronic constipation at the age of 10 years. When she experienced the above symptoms, she was given medical treatments such as an enema, oral magnesium, and oral picosulfate. The frequency of vomiting and abdominal pain increased at the age of 11 years. We performed an enhanced computed tomography (CT) to determine some underlying conditions. We found that the duodenum wall being edematous (Figure 1). Endoscopic examination revealed duodenal stenosis and multiple duodenal ulcers (images not shown). Examination on the biopsized specimen revealed $H$. pylori in the duodenal ulcerative lesions.
${ }^{1}$ Dr. Kazuto Taniguchi, MD. PhD. ${ }^{2} \mathrm{Dr}$. Takema Nakashima, MD, ${ }^{3} \mathrm{Dr}$. Yasunobu Ichiyama, MD. ${ }^{4}$ Dr. Hirokazu Yamamoto, MD, ${ }^{5}$ Dr. Kazuyasu Uemichi, MD. All from Tara Town Hospital, 1520-12 Tara, Saga, 849-1602, Japan.

\section{Address for correspondence \\ Dr. Kazuto Taniguchi \\ E-mail: tgene1@po.hagakure.ne.jp}

\section{How to cite}

Taniguchi K, Nakashima T, Ichiyama Y, Yamamoto H, Uemichi K. Duodenal Stenosis Caused by Helicobacter Pylori: Mimicker of Chronic Constipation. J Nepal Paediatr Soc 2017;37(2):194-196.

doi: http://dx.doi.org/10.3126/jnps.v37i2.18142

This work is licensed under a Creative Commons Attribution 3.0 License.

\section{(c) (i)}



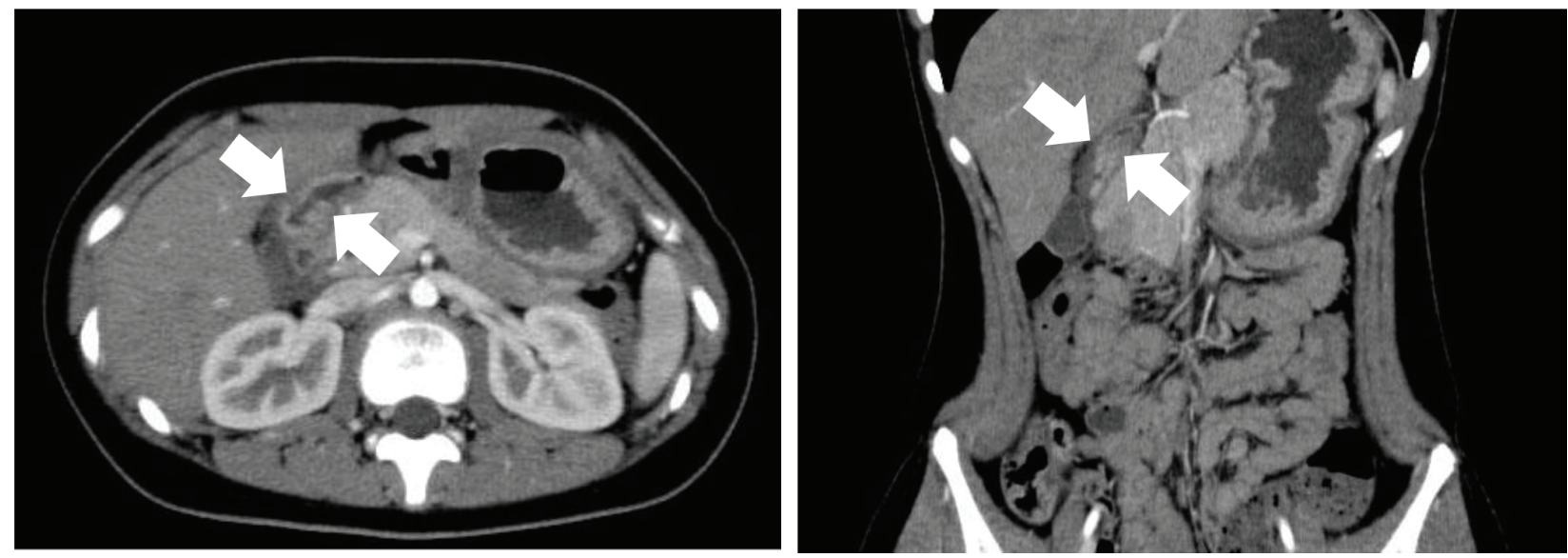

Fig 1: Edematous changes (arrows) in the duodenum were detected by an enhanced CT scan.

She received medications to eradicate $H$. pylori. A urea breath test was employed to evaluate the effectiveness of the eradication. The first-line agents administered, including clarithromycin, amoxicillin, and vonoprazan, did not eradiate $H$. pylori. The secondline agents administered, including metronidazole, amoxicillin, and vonoprazan, successfully eradicated $H$. pylori. After the eradication, she has not suffered from repeated vomiting and abdominal pain for more than 11 months. Endoscopic examination revealed amelioration of duodenal stenosis and duodenal ulcers.

\section{Discussion}

The courses of the present case illustrate two important clinical issues. First, duodenal stenosis can be a mimicker of childhood chronic constipation. The symptoms of duodenal stenosis and chronic constipation include repeated vomiting and abdominal pain. Correct diagnosis is important because the treatments for these diagnoses are different. The present patient's course well illustrated the pitfalls for management of childhood chronic constipation.

Second, an enhanced CT may be useful for examining the underlying conditions in pediatric patient with chronic constipation. Presently, CT revealed duodenal stenosis. CT can be performed on children with little invasiveness and it promptly give us information of the organ structure. The duodenal edema/swelling here revealed by CT was non-specific; however this prompted us to employ further strategies, including an endoscopic examination, leading to a definitive diagnosis.
Chronic constipation is a common and long-lasting childhood disorder ${ }^{6,7}$. Careful consideration of the medical history and a physical examination can exclude other differential diagnoses in most patients without thorough medical examinations. Dietary interventions, behavioral modifications, and oral medicines, such as magnesium, lactulose, and sorbitol, are recommended to ensure that bowel movements occur at normal intervals with good evacuation in the daily management of constipation ${ }^{4,8,9}$. When the management is complex, there is concern that an organic disease may exist, and pediatricians should reevaluate the diagnosis. The present patient's course demonstrated that duodenal stenosis caused by $H$. pylori may be one of the differential diagnoses for pediatric chronic constipation. Eradication using antibiotics and a proton pump inhibitor may ameliorate duodenal stenosis caused by $H$. pylori. An indwelling stent ${ }^{10,11}$ and duodenectomy ${ }^{12}$, which are highly invasive for children, should be considered in severe duodenal stenosis cases. Eradication of $\mathrm{H}$. pylori ameliorated duodenal stenosis in the present patient without an invasive procedure.

\section{Conclusion}

Duodenal stenosis can be a mimicker of chronic constipation. An enhanced CT is useful to detect some organic underlying conditions behind pediatric chronic constipation. We should be aware that pitfalls can be hidden even in usual management of chronic constipation. Further studies are needed to determine whether duodenal stenosis caused by $H$. pylori can become a major differential diagnosis for childhood chronic constipation.

2. Pijpers MA, Bongers ME, Benninga MA, Berger MY. Functional constipation in children: a systematic review on prognosis and predictive factors. $J$ Pediatr Gastroenterol Nutr 2010;50(3):256-68. DOI: 10.1097/ MPG.0b013e3181afcdc3. 
3. Felt $B$, Wise CG, Olson A, Kochhar P, Marcus $\mathrm{S}$, Coran A. Guideline for the management of pediatric idiopathic constipation and soiling. Arch Pediatr Adolesc Med 1999;153(4):380-85. DOI:10.1001/ archpedi.153.4.380

4. Constipation Guideline Committee of the North American Society for Pediatric Gastroenterology, Hepatology and Nutrition. Evaluation and treatment of constipation in infants and children: recommendations of the North American Society for Pediatric Gastroenterology, Hepatology and Nutrition. J Pediatr Gastroenterol Nutr 2006;43(3):e1-e13.

5. Southwell BR, King SK, Hutson JM. Chronic constipation in children: organic disorders are a major cause. J Paediatr Child Health 2005;41(1-2):1-15.

6. Culbert TP, Banez GA. Integrative approaches to childhood constipation and encopresis. Pediatr Clin North Am 2007;54(6):927-47.

7. Mugie SM, Di Lorenzo C, Benninga MA. Constipation in childhood. Net Rev Gastroenterol Hepatol 2011;8(9):502-11. DOI:10.1038/nrgastro.2011.130
8. Nurko S, Zimmerman LA. Evaluation and treatment of constipation in children and adolescents. Am Fam Physician 2014;90(2):82-90.

9. Benninga MA, Voskuijl WP, Taminiau JA. Childhood constipation: is there new light in the tunnel. $J$ Pediatr Gastroenterol Nutr 2004;39(5):448-64.

10. Stawowy M, Kruse A, Mortensen FV, Funch-Jensen P. Endoscopic stenting for malignant gastric outlet obstruction. Surg Laparosc Endosc Percutan Tech 2007;17(1):5-9.

11. Maetani I, Nambu T, Omuta S, Ukita T, Shigoka H. Treating bilio-duodenal obstruction: combining new endoscopic technique with $6 \mathrm{Fr}$ stent introducer. World J Gastroenterol 2010;16(22):2828-831.

12. Chang TM, Chen TH, Shih CM, Gueng MK, Tsou SS. Partial or complete circular duodenectomy with highly selective vagotomy for severe obstructing duodenal ulcer disease: an initial experience. Arch Surg 1998;133(9):998-1001. 